\title{
Quantifying Labile Protein-Ligand Interactions Using Electrospray Ionization Mass Spectrometry
}

\author{
Amr El-Hawiet, Elena N. Kitova, Lan Liu, and John S. Klassen \\ Alberta Ingenuity Centre for Carbohydrate Science, Department of Chemistry, University of Alberta, \\ Edmonton, Alberta, Canada
}

\begin{abstract}
A new electrospray ionization mass spectrometry (ES-MS) approach for quantifying proteinligand complexes that are prone to in-source (gas-phase) dissociation is described. The method, referred to here as the reference ligand ES-MS method, is based on the direct ES-MS assay and competitive ligand binding. A reference ligand $\left(\mathrm{L}_{\mathrm{ref}}\right)$, which binds specifically to the protein $(\mathrm{P})$, at the same binding site as the ligand $(\mathrm{L})$ of interest, with known affinity and forms a stable protein-ligand complex in the gas phase, is added to the solution. The fraction of $\mathrm{P}$ bound to $\mathrm{L}_{\text {ref, }}$, which is determined directly from the ES mass spectrum, is sensitive to the fraction of $\mathrm{P}$ bound to $\mathrm{L}$ in solution and enables the affinity of $\mathrm{P}$ for $\mathrm{L}$ to be determined. A mathematical framework for the implementation of the method in cases where P has one or two specific ligand binding sites is given. Affinities of two carbohydrate-binding proteins, a single chain fragment of a monoclonal antibody and the lectin concanavalin A, for monosaccharide ligands are reported and the results are shown to agree with values obtained using isothermal titration calorimetry. (J Am Soc Mass Spectrom 2010, 21, 1893-1899) (c) 2010 American Society for Mass Spectrometry
\end{abstract}

$\mathrm{T}$ The direct electrospray ionization mass spectrometry (ES-MS) assay has emerged as a powerful technique for quantifying binding constants $\left(\mathrm{K}_{\mathrm{a}}\right)$ for protein-ligand interactions, as well as other noncovalent biological complexes, in solution [1-3]. The assay is based on the direct detection and quantification of the abundance $(A b)$ of ligand-bound and unbound protein ions in the gas phase, e.g., $\mathrm{PL}^{n+}$ and $\mathrm{P}^{n+}$, respectively. A key assumption is that the measured abundance ratio $(R)$ is equivalent to the equilibrium concentration ratio of ligand-bound and free protein in solution, eq 1:

$$
\frac{[\mathrm{PL}]_{\text {eq }}}{[\mathrm{P}]_{\text {eq }}}=\frac{\sum_{\mathrm{n}} A b\left(\mathrm{PL}^{\mathrm{n}+}\right)}{\sum_{\mathrm{n}} A b\left(\mathrm{P}^{\mathrm{n}+}\right)}=R
$$

From the measured $R$ value and initial concentrations of protein $\left([\mathrm{P}]_{\mathrm{o}}\right)$ and ligand $\left([\mathrm{L}]_{\mathrm{o}}\right), \mathrm{K}_{\mathrm{a}}$ can be calculated, $[4]$ eq 2 :

$$
\mathrm{K}_{\mathrm{a}}=\frac{R}{[\mathrm{~L}]_{0}-\frac{R}{1+R}[\mathrm{P}]_{0}}
$$

Address reprint requests to Dr. J. S. Klassen, Department of Chemistry, University of Alberta, Edmonton, AB T6G 2G2, Canada. E-mail: john. klassen@ualbert.ca
The direct ES-MS assay has been used to measure affinities for a range of protein-ligand complexes, including antibody-antigen, lectin-carbohydrate, enzymesubstrate/inhibitor complexes and, in many instances, the $K_{a}$ values agree well with constants obtained by other analytical methods, including isothermal titration calorimetry (ITC), surface plasmon resonance, and frontal affinity chromatography MS [4-10]. However, there have also been reports of protein-ligand complexes that could not be detected by ES-MS or, if detected, the relative abundance of ligand-bound and unbound protein ions did not match the distribution expected in solution, with less binding observed in the gas phase [11-14]. These anomalous results are often due the occurrence of in-source dissociation, whereby the gaseous complexes undergo partial or complete dissociation during ES-MS analysis. If the gas-phase PL ions are kinetically labile and undergo dissociation during analysis, the magnitude of the measured $R$ value and, correspondingly, the $\mathrm{K}_{\mathrm{a}}$ value will be artificially low. In the extreme case, where no PL ions survive, in-source dissociation will result in a false negative. Recently, it was shown that solution or gas-phase additives can, in some instances, protect complexes from in-source dissociation [12, 15]. However, this approach does have its limitations and the detection of very labile gas-phase complexes, which rapidly dissociate at ambient temperature, by ES-MS remains problematic.

Here, we describe an indirect ES-MS approach to quantify protein-ligand interactions that are highly 
labile and prone to in-source dissociation. The method, referred to as the reference ligand ES-MS method, employs direct ES-MS analysis in conjunction with a reference ligand $\left(\mathrm{L}_{\text {ref }}\right)$. The $\mathrm{L}_{\text {ref }}$ binds specifically to $\mathrm{P}$, at the same binding site as L, with known affinity and forms a stable protein-ligand complex in the gas phase. The fraction of $\mathrm{P}$ bound to $\mathrm{L}_{\mathrm{ref}}$, which is determined directly from the ES mass spectrum, is sensitive to the fraction of $\mathrm{P}$ bound to $\mathrm{L}$ in solution and enables the affinity of the PL complex to be established. A mathematical framework for the implementation of the method in cases where $\mathrm{P}$ has one or two specific ligand binding sites is given. To demonstrate the reliability of the method, monosaccharide affinities were measured for two carbohydrate-binding proteins, a single chain fragment of a monoclonal antibody binding and the lectin concanavalin $\mathrm{A}$, and the values compared with data obtained using ITC.

\section{Experimental}

\section{Proteins and Ligands}

The carbohydrate-binding antibody single chain fragment, Se155-4 scFv (MW 26539 Da), was produced using recombinant technology [16]. The scFv was concentrated and dialyzed against aqueous solution of 50 $\mathrm{mM}$ ammonium acetate ( $\mathrm{pH} 7)$ using microconcentrators (Millipore Corp., Bedford, MA, USA) with a molecular weight cut-off of $10 \mathrm{kDa}$, and lyophilized before MS analysis. The scFv was weighed immediately after removing it from the lyophilizer, dissolved in a known volume of aqueous $50 \mathrm{mM}$ ammonium acetate and stored at $-20^{\circ} \mathrm{C}$ if not used immediately. The proteins concanavalin A (ConA, MW 25600 Da for monomer) and lysozyme (Lyz, MW $14311 \mathrm{Da}$ ) were purchased from Sigma-Aldrich Canada (Oakville, Canada), and used without further purification. The synthetic carbohydrate ligands, abequose methyl glycoside (1), methyl 3-deoxyarabinose (2), methyl- $\alpha$-D-glucopyranoside (3), and $\alpha$ Abe $\left(2-\mathrm{OCH}_{3}-\alpha\right.$ Man $) \alpha$ Glc $\beta$ Glc (4) were provided by Professor D. Bundle (University of Alberta), while methyl- $\alpha$-D-mannopyranoside (5) and $\alpha$-methyl-3,6di-O-( $\alpha$-D-mannopyranosyl)- $\alpha$-D-mannopyranoside (6) were purchased from Toronto Research Chemicals Inc (North York, Canada).

\section{Mass Spectrometry}

All experiments were performed on an Apex II 9.4 tesla Fourier transform ion cyclotron resonance (FT-ICR) mass spectrometers (Bruker, Billerica, MA, USA) equipped with an external nanoflow ES ion source. A description of the instrument and the experimental and instrumental parameters used in the ES-MS binding measurements is given elsewhere [4].

\section{Results and Discussion}

\section{Overview of Reference Ligand Method}

The influence of in-source dissociation on ES-MS mass spectra acquired for a solution of $\mathrm{P}$ and two ligands, $\mathrm{L}$ and $\mathrm{L}_{\mathrm{ref}}$, which bind at the same site, is depicted in Figure 1. In

(a)
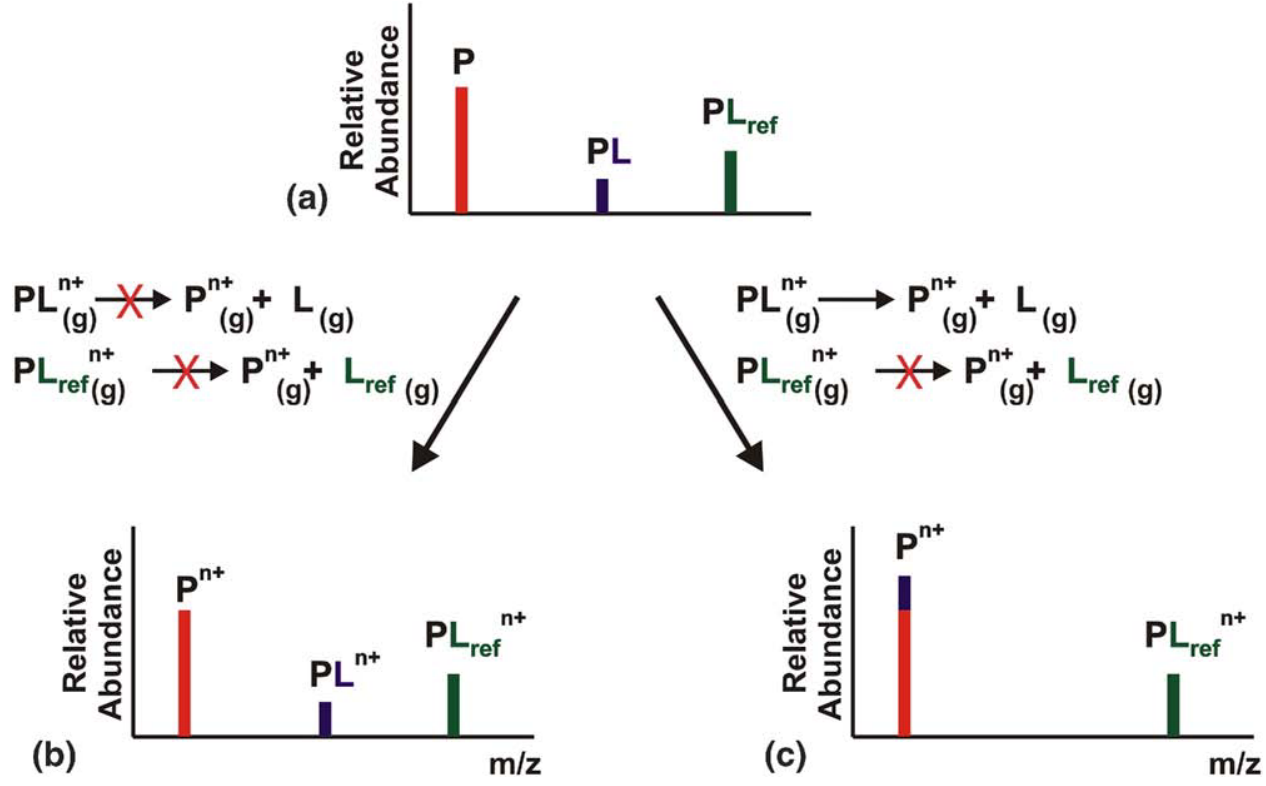

Figure 1. Influence of in-source dissociation on the relative abundance of gas-phase protein-ligand complexes. (a) Hypothetical distribution of species present in solution when ligands $\mathrm{L}$ and $\mathrm{L}_{\text {ref }}$ interact with a single binding site of protein P. (b) In the absence of in-source dissociation, the relative abundance of gas-phase $\mathrm{PL}^{n+}$ and $\mathrm{PL}_{\mathrm{ref}}{ }^{n+}$ ions will reflect the original distribution in solution. (c) In-source dissociation of the $\mathrm{PL}^{n+}$ ions (but not the $\mathrm{PL}_{\mathrm{ref}}{ }^{n+}$ ions) will result in a decrease in the measured abundance ratio of $\mathrm{PL}_{\mathrm{ref}}{ }^{n+}$ to $\mathrm{P}^{n+}$ ions. 
the absence of in-source dissociation (and assuming uniform response factors and an absence of nonspecific ligand binding), the measured abundance ratios of ligand-bound to free $\mathrm{P}$ ions ( $R$ and $\left.R_{\text {ref }}\right)$ will reflect the concentration ratios in solution (Figure $1 \mathrm{a}$ and $\mathrm{b}$ ) and $\mathrm{K}_{\mathrm{a}}$ for the PL complex can be calculated using eq 3:

$$
\mathrm{K}_{\mathrm{a}}=\frac{R}{[\mathrm{~L}]_{0}-\frac{R}{1+R+R_{r e f}}[\mathrm{P}]_{0}}
$$

where $R$ is given by eq 1 and $R_{\text {ref }}$ by eq 4 :

$$
\frac{\left[\mathrm{PL}_{\mathrm{ref}}\right]_{e q}}{[\mathrm{P}]_{e q}}=\frac{\sum_{n} A b\left(\mathrm{PL}_{\mathrm{ref}}{ }^{n+}\right)}{\sum_{n} A b\left(\mathrm{P}^{n+}\right)}=R_{r e f}
$$

If, on the other hand, the gas-phase ions of the PL complex are kinetically labile and undergo in-source dissociation, the relative abundance of ligand-bound and free protein ions measured by ES-MS will no longer reflect the original concentration ratios (Figure 1a and c). In the extreme case where no PL ions survive until detection, the measured abundance ratio of $\mathrm{L}_{\mathrm{ref}}$-bound $\mathrm{P}$ to free $\mathrm{P}$ gas-phase ions (i.e., $R_{\text {ref,app }}$ ) will depend on the concentration of both free $\mathrm{P}$ and $\mathrm{PL}$ originally present in solution, eq 5:

$$
\frac{\left[\mathrm{PL}_{\mathrm{ref}}\right]_{\text {eq }}}{[\mathrm{P}]_{\text {eq }}+[\mathrm{PL}]_{\text {eq }}}=\frac{\sum_{n} A b\left(\mathrm{PL}_{\mathrm{ref}}^{n+}\right)}{\sum_{n} A b\left(\mathrm{P}^{n+}\right)}=R_{\text {ref, app }}
$$

However, if $\mathrm{K}_{\mathrm{a}, \text { ref }}$ is known, $R_{\text {ref }}$ (the "true" concentration ratio $\left.\left[\mathrm{PL}_{\mathrm{ref}}\right] /[\mathrm{P}]\right)$ can be calculated from $R_{\text {ref,app }}$ eq 6:

$$
R_{r e f}=\mathrm{K}_{\mathrm{a}, \mathrm{ref}}\left(\left[\mathrm{L}_{\mathrm{ref}}\right]_{\mathrm{o}}-[\mathrm{P}]_{\mathrm{o}} \frac{R_{\text {ref,app }}}{R_{\text {ref, app }}+1}\right)
$$

Furthermore, the magnitude of $R$ can be calculated from the corresponding $R_{\text {ref,app }}$ and $R_{\text {ref }}$ values, eq 7:

$$
R=\frac{R_{\text {ref }}}{R_{\text {ref, app }}}-1
$$

Once $R$ and $R_{\text {ref }}$ are known, the $\mathrm{K}_{\mathrm{a}}$ value for the PL complex can be calculated using eq 3 .

It should be noted that the above treatment can easily be extended to the case where the gas-phase PL ions undergo partial dissociation in the source. In this situation, $R_{\text {ref }}$ can be determined from the measured abundance ratio of $\mathrm{L}_{\text {ref }}$-bound $\mathrm{P}$ to free $\mathrm{P}$ gas-phase ions (i.e., $R_{\text {ref,app }}$ ) and the measured abundance ratio of L-bound $\mathrm{P}$ to free $\mathrm{P}$ gas-phase ions (i.e., $R_{\text {app }}$ ) using eq 8 :

$$
R_{r e f}=K_{a, r e f}\left(\left[L_{r e f}\right]_{o}-[P]_{o} \frac{R_{r e f, a p p}}{R_{r e f, a p p}+R_{a p p}+1}\right)
$$

and $R$ can be found using eq 9:

$$
R=\frac{\left(1+R_{a p p}\right)}{R_{\text {ref,app }}} R_{\text {ref }}-1
$$

Once $R$ and $R_{\text {ref }}$ are known, $\mathrm{K}_{\mathrm{a}}$ can be calculated in the usual way.

Because many proteins possess multiple ligand binding sites, it is also useful to consider how the reference ligand ES-MS method can be applied to these situations. Given below are the relevant mathematical expressions for the application of the method for the case where $\mathrm{P}$ possesses two equivalent and independent ligand binding sites. Expressions for the equilibrium constants $\left(\mathrm{K}_{\mathrm{a}, 1}\right.$ and $K_{a, 2}$ ) for the sequential binding of $L$ to $P$ in the presence of $\mathrm{L}_{\text {ref }}$, written in terms of the concentration ratios of ligand bound ( $\mathrm{L}$ or $\mathrm{L}_{\mathrm{ref}}$ ) $\mathrm{P}$ to free $\mathrm{P}$, are:

$$
\begin{aligned}
& \mathrm{K}_{a, 1}= \frac{R_{1,0}}{[\mathrm{~L}]_{\mathrm{o}}-\frac{\left(R_{1,0}+2 R_{2,0}+R_{1,1}\right)[\mathrm{P}]_{\mathrm{o}}}{1+R_{1,0}+R_{2,0}+R_{0,1}+R_{1,1}+R_{0,2}}} \\
& \mathrm{~K}_{a, 2}=\frac{R_{2,0}}{R_{1,0}\left([\mathrm{~L}]_{\mathrm{o}}-\frac{\left(R_{1,0}+2 R_{2,0}+R_{1,1}\right)[\mathrm{P}]_{\mathrm{o}}}{1+R_{1,0}+R_{2,0}+R_{0,1}+R_{1,1}+R_{0,2}}\right)}
\end{aligned}
$$

where $R_{i, j}$ is the concentration ratio of ligand-bound $\mathrm{P}$ (to $i$ molecules of $\mathrm{L}$ and $j$ molecules of $\mathrm{L}_{\text {ref }}$ ) to free P. As before, in the absence of in-source dissociation, the $R_{i, j}$ values can be determined directly from the relative abundance of ligand-bound and free $\mathrm{P}$ ions measured by ES-MS, eq 11:

$$
\frac{\left[\mathrm{P}(\mathrm{L})_{i}\left(\mathrm{~L}_{\mathrm{ref}}\right)_{j}\right]_{e q}}{[\mathrm{P}]_{e q}}=\frac{\sum_{\mathrm{n}} A b\left(\mathrm{PL}_{i} \mathrm{~L}_{\mathrm{ref}, j}{ }^{\mathrm{n}+}\right)}{\sum_{\mathrm{n}} A b\left(\mathrm{P}^{\mathrm{n}+}\right)}=R_{i, j}
$$

However, if in-source dissociation takes place, the measured ratios will no longer reflect solution composition. In the extreme case, where none of the P-L interactions survive the ion source, only the ratios $R_{0,1 a p p}$ and $R_{0,2 a p p}$ can be determined from the ES mass spectrum:

$$
\begin{aligned}
& \frac{\sum_{\mathrm{n}} A b\left(\mathrm{PL}_{\mathrm{ref}}^{\mathrm{n}+}\right)}{\sum_{\mathrm{n}} A b\left(\mathrm{P}^{\mathrm{n}+}\right)}=R_{0,1 a p p} \\
& \frac{\sum_{\mathrm{n}} A b\left(\mathrm{P}\left(\mathrm{L}_{\mathrm{ref}}\right)_{2}^{\mathrm{n}+}\right)}{\sum_{\mathrm{n}} A b\left(\mathrm{P}^{\mathrm{n}+}\right)}=R_{0,2 a p p}
\end{aligned}
$$

Using the known values of $\mathrm{K}_{\mathrm{a} 1, \text { Lref, }}\left[\mathrm{L}_{\text {ref }}\right]_{\mathrm{o}},[\mathrm{P}]_{\mathrm{o}}, R_{0,1 \text { app }}$ and $R_{0,2 a p p}$, the $R_{i, j}$ terms can be calculated using following expressions:

$$
R_{0,1}=\mathrm{K}_{\mathrm{a} 1, \text { Lref }}\left(\left[\mathrm{L}_{\mathrm{ref}}\right]_{0}-[\mathrm{P}]_{0} \frac{R_{0,1 a p p}+2 R_{0,2 a p p}}{1+R_{0,1 a p p}+R_{0,2 a p p}}\right)
$$




$$
\begin{aligned}
& R_{0,2}=\left(R_{0,1}\right)^{2} / 4 \\
& R_{1,1}=\frac{R_{0,1 \text { app }} R_{0,2}}{R_{0,2 a p p}}-R_{0,1} \\
& R_{1,0}=-2+2 \sqrt{\frac{R_{0,2}}{R_{0,2 a p p}}} \\
& R_{2,0}=1+\frac{R_{0,2}}{R_{0,2 a p p}}-2 \sqrt{\frac{R_{0,2}}{R_{0,2 a p p}}}
\end{aligned}
$$

and $K_{a, 1}$ and $K_{a, 2}$ can be calculated using eqs 10a and $10 \mathrm{~b}$.

The two basic requirements for a suitable $\mathrm{L}_{\text {ref }}$ are that it binds specifically to $\mathrm{P}$ in solution, at the same binding site as L, with a known affinity and that it forms a stable protein-ligand interaction in the gas phase, i.e., is resistant to in-source dissociation. In addition, there are several other practical considerations. It is desirable to use a reasonably strong binding ligand as $\mathrm{L}_{\text {ref, }}$ with a $\mathrm{K}_{\mathrm{a} \text {,ref }}$ of $10^{5}-10^{7} \mathrm{M}^{-1}$, since in this case $R_{\text {ref }}$ and $R_{\text {ref,app }}$ are more sensitive to the presence of the competing ligand. Additionally, changes in $R_{\text {ref }}$ are more pronounced when low protein concentrations $(\sim \mu \mathrm{M})$ are used. Finally, depending on the magnitude of $\mathrm{K}_{\mathrm{a}}$ and $\mathrm{K}_{\mathrm{a} \text {,ref, }}$, the concentrations of $\mathrm{P}$ and both ligands ( $\mathrm{L}$ and $\mathrm{L}_{\mathrm{ref}}$ ) may need to be adjusted so that both complexes are present in solution at significant concentrations.

\section{Determination of Protein-Ligand Affinities}

To demonstrate the reliability of the reference ligand ES-MS method for quantifying protein-ligand interactions that are not readily detected by ES-MS, binding measurements were carried out on two carbohydratebinding proteins, Se155-4 scFv and ConA. Association constants have been determined by ITC for the binding of Se155-4 scFv to the monosaccharides $1\left(1.5 \times 10^{3}\right.$ $\left.\mathrm{M}^{-1}\right)$ and $2\left(1.2 \times 10^{2} \mathrm{M}^{-1}\right)$ at $\mathrm{pH} 7$ and $25^{\circ} \mathrm{C}$ [17]. The monosaccharide 3 , which was shown by ITC not to bind to the scFv [Bundle, D.R., Unpublished results], served as a negative control. Con $\mathrm{A}$ is a tetramer above $\mathrm{pH} 7$ and a dimer below $\mathrm{pH}$ 6. Each subunit possesses a single carbohydrate binding site with specificity for the $\alpha$-pyranose forms of Glc or Man. The affinity of dimeric ConA for the monosaccharide 5 was determined to be $(7.9 \pm 1.0) \times 10^{3} \mathrm{M}^{-1}$ at $\mathrm{pH} 5.2$ and $25^{\circ} \mathrm{C}$ by ITC [18].

\section{scFv-Monosaccharide Binding}

Shown in Figure 2a is a representative ES mass spectrum acquired for a solution of $\mathrm{scFv}(10 \mu \mathrm{M})$ and $\mathbf{1}(1$ $\mathrm{mM}$ ) at $\mathrm{pH} 7$ and $25^{\circ} \mathrm{C}$. A reference protein (Lyz) was also added to monitor for the occurrence of non-specific ligand binding to $\mathrm{scFv}$ during the ES process [19]. At these concentrations, $60 \%$ of the $\mathrm{scFv}$ is expected to be bound to $\mathbf{1}$ in solution. However, no gas-phase ions corresponding to the specific $(\mathrm{scFv}+\mathbf{1})$ complex were detected, indicating the occurrence of in-source dissociation. Attempts to stabilize the complex during ES-MS analysis using a high concentration $(10 \mathrm{mM})$ of imidazole, a stabilizing additive [12], were unsuccessful (data not shown). The instability of the gas-phase ions of the $(\mathrm{scFv}+1)$ complex can be explained by the small number of intermolecular hydrogen bonds that $\mathbf{1}$ is capable of making. Direct ES-MS analysis of solutions of scFv $(10 \mu \mathrm{M})$ with $2(2 \mathrm{mM})$ or $3(1 \mathrm{mM})$ also failed to detect ions of the $(\mathrm{scFv}+2)$ or $(\mathrm{scFv}+3)$ complex (data not shown). In contrast, ES-MS analysis of a solution of scFv $(10 \mu \mathrm{M})$ and $4(59 \mu \mathrm{M})$ clearly identified the presence of gas-phase ions corresponding to the $(\mathrm{scFv}+$ 4) complex, Figure $2 b$. The $K_{a}$ value determined directly from the ES mass spectrum, following correction for nonspecific ligand binding [19], was $(1.6 \pm 0.5) \times 10^{5}$ $\mathrm{M}^{-1}$. Shown in Figure $2 \mathrm{c}$ is a representative ES mass spectrum acquired for a solution of scFv $(10 \mu \mathrm{M}), 1$ (1 $\mathrm{mM})$ and $4(59 \mu \mathrm{M})$. Although ions corresponding to the $(\mathrm{scFv}+1)$ complex were not detected, the addition of $\mathbf{1}$ to the solution resulted in a decrease in the fraction of $\mathrm{scFv}$ bound to 4 , indicating the presence of specific binding between $\mathrm{scFv}$ and $\mathbf{1}$ in solution. Plotted in Figure 3 is the fraction of bound (to 4 ) and unbound $\mathrm{scFv}$ determined by direct ES-MS measurements at fixed concentrations of $\mathrm{scFv}(10 \mu \mathrm{M})$ and $4(59 \mu \mathrm{M})$ and varying concentrations of $\mathbf{1}(0,500,1000$, and $2000 \mu \mathrm{M})$. Notably, the fraction of scFv bound to 4 decreased with increasing concentration of 1 . Analysis of the ES-MS data using the approach described above leads to an average $\mathrm{K}_{\mathrm{a}}$ value of $(1.4 \pm 0.3) \times 10^{3} \mathrm{M}^{-1}$ for the $(\mathrm{scFv}+$ 1) complex, Table 1 . This value is indistinguishable, within experimental error, from the ITC-derived value of $(1.5 \pm 0.4) \times 10^{3} \mathrm{M}^{-1}$ [17]. Following the same approach, a $\mathrm{K}_{\mathrm{a}}$ value of $(1.7 \pm 0.9) \times 10^{2} \mathrm{M}^{-1}$ was determined for the $(\mathrm{scFv}+2)$ complex, which is also in good agreement with the ITC value of $(1.2 \pm 0.5) \times 10^{2} \mathrm{M}^{-1}$ [17]. In contrast, the assay did not detect any binding between the scFv and 3 , consistent with the results of ITC measurements [Bundle, D.R., Unpublished results].

\section{ConA-Monosaccharide Binding}

To demonstrate that the reference ligand ES-MS method is generally applicable to the quantification of labile protein-ligand interactions, the method was also used to measure the affinity of the lectin ConA for the monosaccharide 5 . The binding measurements were performed at $\mathrm{pH}$ 5.2, where ConA exists predominantly as a homodimer. At this $\mathrm{pH}$, ConA is known to bind the monosaccharide $\mathbf{5}$, as well as oligomannose ligands such as 6, which served as $\mathrm{L}_{\text {ref }}$ for these measurements [20]. Importantly, it was previously shown that 5 and $\mathbf{6}$ bind in the same binding site [21]. In an earlier study, it was reported that the ConA-5 interaction is quite labile in the gas phase and can be, depending on the ES-MS instrumentation used, difficult to detect [11]. In the present work, it was found that the complex could be 


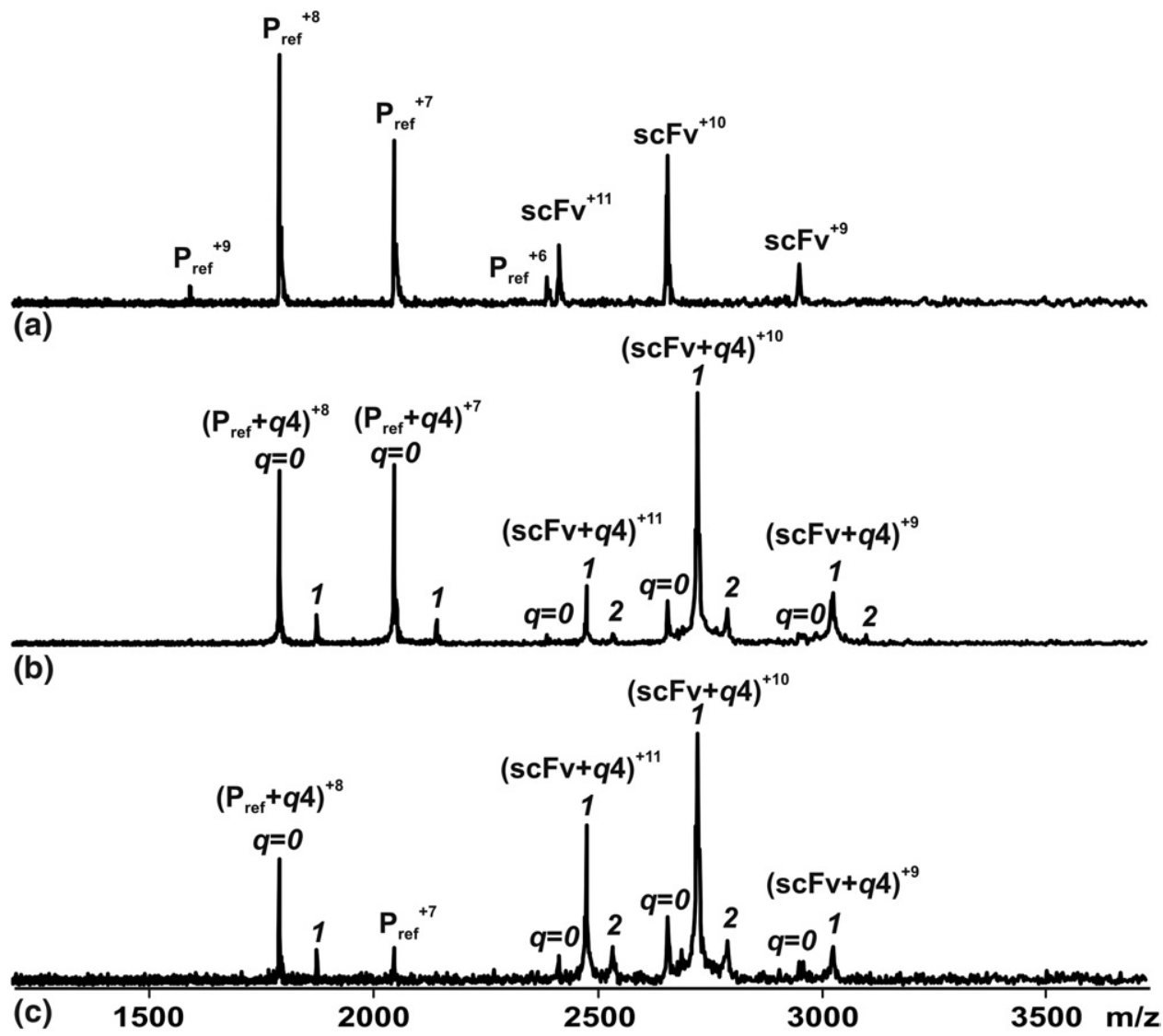

Figure 2. ES mass spectra obtained for the solutions of Se155-4 scFv $(10 \mu \mathrm{M})$ and (a) $\mathbf{1}(1000 \mu \mathrm{M}),(\mathbf{b})$ $4(59 \mu \mathrm{M})$, and $(\mathrm{c}) 4(59 \mu \mathrm{M})$ and $1(1000 \mu \mathrm{M})$. The number of molecules of 4 bound to the protein ions is indicated by $q$.

directly detected by ES-MS. However, the relative abundance of the ligand-bound forms of ConA dimer was sensitive to ion source conditions, such as hexapole accumulation time. To demonstrate the reliability of the assay in cases where the complex could not be directly detected, source conditions that lead to complete dissociation of the ConA-5 interactions were used.

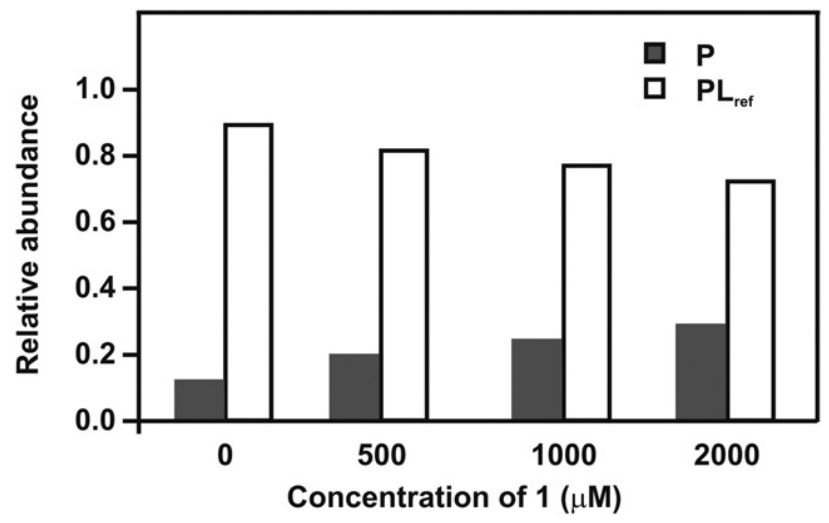

Figure 3. Distribution of the relative abundance of $\mathrm{scFv}(\equiv \mathrm{P})$ and $(\mathrm{scFv}+4)$ complex $\left(\equiv \mathrm{PL}_{\mathrm{ref}}\right)$ measured by ES-MS for solutions of scFv $(10 \mu \mathrm{M}), 4(59 \mu \mathrm{M})$, and 1 at concentrations of $0,500,1000$, and $2000 \mu \mathrm{M}$.
Shown in Figure 4a is an ES mass spectrum measured for a solution of ConA ( $30 \mu \mathrm{M}$ for monomer) at $\mathrm{pH}$ 5.2. Notably, only ions corresponding to ConA homodimer $\left(\mathrm{ConA}_{2}\right)$ were identified; no ions corresponding to monomer or homotetramer were detected. Upon addition of $6(15 \mu \mathrm{M})$ to the solution, ions corresponding to Con $\mathrm{A}_{2}$ bound to one and two molecules of 6 were also detected (Figure $4 \mathrm{~b}$ ). The intrinsic affinity of Con $\mathrm{A}_{2}$ for $\mathbf{6}$, based on the $\mathrm{K}_{\mathrm{a}, 1}$ and $\mathrm{K}_{\mathrm{a}, 2}$ values determined directly from the ES mass spectra, is ( $5 \pm$ 2) $\times 10^{5} \mathrm{M}^{-1}$. This value is in excellent agreement with

Table 1. Association constants $\left(\mathrm{K}_{\mathrm{a}}\right)$ for carbohydrate ligand binding to Se155-4 scFv and ConA determined by the ES-MS reference ligand method and by ITC at $25^{\circ} \mathrm{C}^{\mathrm{a}}$

\begin{tabular}{lcccc}
\hline Protein & Ligand & $\mathrm{pH}$ & $\begin{array}{c}\mathrm{ES}-\mathrm{MS} \mathrm{K}_{a} \times \\
10^{-3}\left(\mathrm{M}^{-1}\right)\end{array}$ & $\begin{array}{c}\mathrm{ITC} \mathrm{K}_{a} \times \\
10^{-3}\left(\mathrm{M}^{-1}\right)\end{array}$ \\
\hline \hline scFv & $\mathbf{1}$ & 7.0 & $1.4 \pm 0.3$ & $1.5 \pm 0.4^{\mathrm{b}}$ \\
ScFv & $\mathbf{2}$ & 7.0 & $0.17 \pm 0.09$ & $0.12 \pm 0.05^{\mathrm{b}}$ \\
scFv & $\mathbf{3}$ & 7.0 & $\mathrm{NB}^{\mathrm{c}}$ & $\mathrm{NB}^{\mathrm{c}}$ \\
ConA & $\mathbf{5}$ & 5.2 & $10 \pm 4^{\mathrm{d}}$ & $7.9 \pm 1.0^{\mathrm{d}, \mathrm{e}}$ \\
\hline
\end{tabular}

${ }^{\text {aE}}$ Errors correspond to one standard deviation.

bValues taken from reference [16].

${ }^{\mathrm{C}} \mathrm{NB} \equiv$ No binding detected.

dValues correspond to average intrinsic $\mathrm{K}_{\mathrm{a}}$ for dimeric ConA.

'Value taken from reference [18]. 


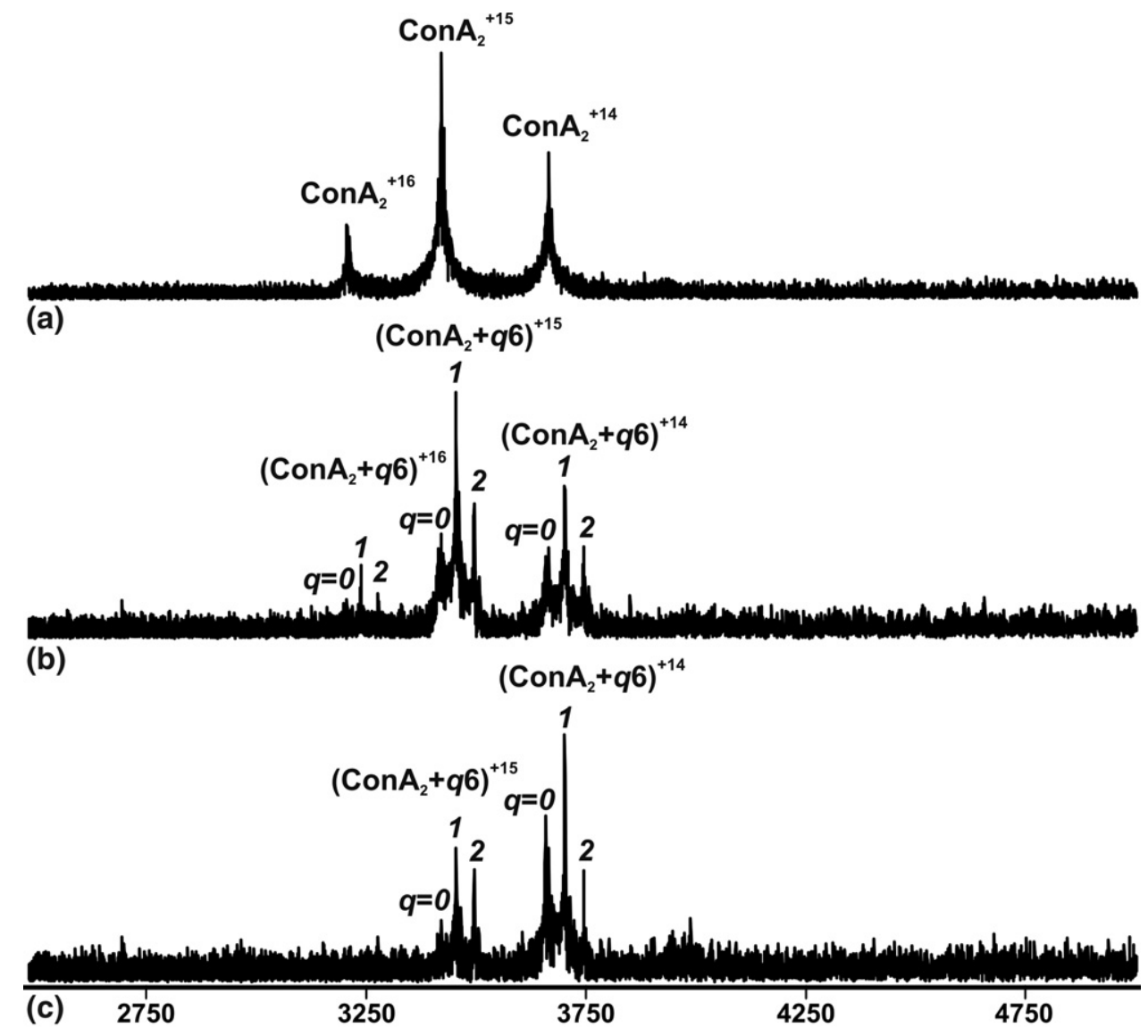

Figure 4. ES mass spectra obtained for the solutions of (a) Con $\mathrm{A}_{2}(15 \mu \mathrm{M})$ alone and with (b) 6 (15 $\mu \mathrm{M})$, and $(\mathrm{c}) \mathbf{6}(15 \mu \mathrm{M})$ and $5(100 \mu \mathrm{M})$. The number of molecules of 6 bound to the protein ions is indicated by $q$.

a value of $(5.1 \pm 0.2) \times 10^{5} \mathrm{M}^{-1}$ that was determined by ITC for homodimer of ConA at $\mathrm{pH} 5.2$ [20]. Under the experimental conditions used, ES-MS analysis of a solution of $\mathrm{ConA}_{2}(13 \mu \mathrm{M})$ with $5(50$ or $100 \mu \mathrm{M})$ and 6 $(15 \mu \mathrm{M})$ led to the detection of ions corresponding to Con $\mathrm{A}_{2}$ bound to one and two molecules of 6 but not ions corresponding to $\mathrm{ConA}_{2}$ bound to 5 (Figure $4 \mathrm{c}$ ). However, the addition of 5 to the solution did result in a small but measurable reduction in the fraction of Con $\mathrm{A}_{2}$ bound to 6 . Following the procedures outlined above, the intrinsic $\mathrm{K}_{\mathrm{a}}$ for the Con $\mathrm{A}_{2}-\mathbf{5}$ interaction was determined to be $(1.0 \pm 0.4) \times 10^{4} \mathrm{M}^{-1}$, which is in reasonable agreement with the ITC-derived value of $(7.9 \pm 1.0) \times 10^{3} \mathrm{M}^{-1}[18]$, Table 1 .

\section{Conclusions}

In summary, an ES-MS approach for quantifying protein-ligand interactions that are prone to in-source dissociation and, therefore, difficult to detect directly is described. The reference ligand ES-MS method employs the direct ES-MS assay in conjunction with a $\mathrm{L}_{\text {ref, }}$ which binds competitively to protein of interest with known affinity and forms a stable complex in the gas-phase. The relative abundance of $\mathrm{L}_{\mathrm{ref}}$-bound protein to free protein, which can be measured directly by ES-MS, is sensitive to the presence of other ligands in solution that compete for the same binding site. As a result, it is possible to quantify protein-ligand interactions that are unstable in the gas-phase by measuring the relative abundance of $\mathrm{L}_{\mathrm{ref}}$-bound protein using the direct ES-MS assay. The relevant mathematical expressions for the implementation of the method for proteins with a single ligand binding site or two equivalent binding sites are given. To demonstrate the reliability of the method, the binding of monosaccharide ligands to two carbohydratebinding proteins was quantified. Importantly, the carbohydrate affinities were found to be in good agreement with values measured using ITC. It is anticipated that this method will prove particularly useful in extending the application of ES-MS binding measurements to protein interactions with small or hydrophobic ligands and for implementing a small fragment approach to the elucidating details of protein-oligosaccharide interactions [22].

\section{References}

1. Daniel, J. M.; Friess, S. D.; Rajagopalan, S.; Wendt, S.; Zenobi, R. Quantitative Determination of Noncovalent Binding Interactions Using Soft Ionization Mass Spectrometry. Int. J. Mass Spectrom. 2002, 216, 1-27. 
2. Schug, K. A. Solution Phase Enantioselective Recognition and Discrimination by Electrospray Ionization-Mass Spectrometry: State-of-the-Art Methods and an Eye Towards Increased Throughput Measurements. Comb. Chem. High Throughput Screen. 2007, 10, 301-316.

3. Heck A. J. R.; Van Den. Heuvel R. H. H. Investigation of Intact Protein Complexes by Mass Spectrometry. Mass Spectrom. Rev. 2004, 23, 368389.

4. Wang, W.; Kitova, E. N.; Klassen, J. S. Influence of Solution and Gas Phase Processes on Protein-Carbohydrate Binding Affinities Determined by Nanoelectrospray Fourier-Transform Ion Cyclotron Resonance Mass Spectrometry. Anal. Chem. 2003, 75, 4945-4955.

5. Shoemaker, G. K.; Soya, N.; Palcic, M. M.; Klassen, J. S. TemperatureDependent Cooperativity in Donor-Acceptor Substrate Binding to the Human Blood Group Glycosltransferases. Glycobiology 2008, 18, 587592.

6. Soya, N.; Shoemaker, G. K.; Palcic, M. M.; Klassen, J. S. Comparative Study of Substrate and Product Binding to the Human $\mathrm{ABO}(\mathrm{H})$ Blood Group Glycosyltransferases. Glycobiology 2009, 19, 1224-1234.

7. Rademacher, C.; Shoemaker, G. K.; Kim, H.-S.; Zheng, R. B.; Taha, H.; Liu, C.; Nacario, R. C.; Schriemer, D. C.; Klassen, J. S.; Peters T.; Lowary, T. L. Ligand Specificity of CS-35, a Monoclonal Antibody That Recognizes Mycobacterial Lipoarabinomannan. A Model System for OligofuranosideProtein Recognition. J. Am. Chem. Soc. 2007, 129, 10489-10502.

8. Jorgensen, T. J. D.; Roepstorff, P.; Heck, A. J. R. Direct Determination of Solution Binding Constants for Noncovalent Complexes Between Bacterial Cell Wall Peptide Analogues and Vancomycin Group Antibiotics by Electrospray Ionization Mass Spectrometry. Anal. Chem. 1998, 70, 4427-4432.

9. Jecklin, M. C.; Touboul, D.; Bovet, C.; Wortmann, A.; Zenobi, R. Which Electrospray-Based Ionization Method Best Reflects Protein-Ligand Interactions Found in Solution? A Comparison of ESI, nanoESI, and ESSI for the Determination of Dissociation Constants with Mass Spectrometry. J. Am. Soc. Mass Spectrom. 2008, 19, 332-343.

10. Yu, Y. H.; Kirkup, C., E.; Pi, N.; Leary, J. A. Characterization of Noncovalent Protein-Ligand Complexes and Associated Enzyme Intermediates of GlcNAc-6-O-Sulfotransferase by Electrospray Ionization FT-ICR Mass Spectrometry. J. Am. Soc. Mass Spectrom. 2004, 15, 1400-1407.

11. Van Dongen, W. D.; Heck, A. J. R. Binding of Selected Carbohydrates to apo-Concanavalin A Studied by Electrospray Ionization Mass Apectrometry. Analyst 2000, 125, 583-589.
12. Sun, J.; Kitova, E. N.; Klassen, J. S. Method for Stabilizing ProteinLigand Complexes in Nanoelectrospray Ionization Mass Spectrometry. Anal. Chem. 2007, 79, 416-425.

13. Clark, S. M.; Konermann, L. Determination of Ligand-Protein Dissociation Constants by Electrospray Mass Spectrometry-Based Diffusion Measurements. Anal. Chem. 2004, 76, 7077-7083.

14. Robinson, C. V.; Chung, E. W.; Kragelund, B. B.; Knudsen, J.; Aplin, R. T.; Poulsen, F. M.; Dobson, C. M. Probing the Nature of Noncovalent Interactions by Mass Spectrometry. A study of Protein-CoA Ligand Binding and Assembly. J. Am. Chem. Soc. 1996, 118, 8646-8653.

15. Bagal, D.; Kitova, E. N.; Liu, L.; El-Hawiet, A.; Schnier, P. D.; Klassen, J. S. Gas Phase Stabilization of Noncovalent Protein Complexes Formed by Electrospray Ionization. Anal. Chem. 2009, 81, 7801-7806.

16. Zdanov, A.; Bundle, D. R.; Deng, S.-J.; MacKenzie, C. R.; Narang, S. A.; Young, M. N.; Cygler, M. Structure of a Single-Chain Antibody Variable Domain (fv) Fragment Complexed with a Carbohydrate Antigen at 1.7 A Resolution. Proc. Natl. Acad. Sci. U.S.A. 1994, 91, 6423-6427.

17. Bundle, D. R.; Eichler, E.; Gidney, M. A. J.; Meldal, M.; Ragauskas, A.; Sigurskjold, B. W.; Sinnott, B.; Watson, D. C.; Yaguchi, M.; Young, N. M. Molecular Recognition of a Salmonella trisaccharide Epitope by Monoclonal Antibody Se155-4. Biochemistry 1994, 33, 5172-5182.

18. Castro, S.; Duff, M.; Snyder, N. L.; Morton, M.; Kumar, C. V.; Peezuh, M. W. Recognition of Septanose Carbohydrates by Concanavalin A. Org. Biomol. Chem. 2005, 3, 3869-3872.

19. Sun, J.; Kitova, E. N.; Wang, W.; Klassen, J. S. Method for Distinguishing Specific and Nonspecific Protein-Ligand Complexes in Nanoelectrospray Ionization Mass Spectrometry. Anal. Chem. 2006, 78, 3010-3018.

20. Mandal, D. K. Brewer, C. F. Differences in the Binding Affinities of Dimeric Concanavalin-a (Including Acetyl and Succinyl Derivatives) and Tetrameric Concanavalin-a with Large Oligomannose-Type Glycopeptides. Biochemistry 1993, 32, 5116-5120.

21. Loris, R.; Maes, D.; Poortmans, F.; Wyns, L.; Bouckaert, J. A Structure of the Complex Between Concanavalin a and Methyl-3,6-di-O- $(\alpha-\mathrm{D}-$ Mannopyranosyl)- $\alpha$-D-Pyranoside Reveals Two Binding Modes. J. Biol. Chem. 1996, 271, 30614-30618.

22. de Kloe, G. E.; Bailey, D.; Leurs, R.; de Elch, I. J. P. Transforming Fragments into Candidates: Small Becomes Big in Medicinal Chemistry. Drug Discov. Today 2009, 14, 630-646. 